\title{
Preventing Environmental Disasters in Investment under Uncertainty
}

\author{
Peter Kort ${ }^{1,2} \cdot$ Maria Lavrutich $^{3}$ (D) $\cdot$ Cláudia Nunes $^{4} \cdot$ Carlos Oliveira $^{5,6}$
}

Accepted: 3 September 2021 / Published online: 14 September 2021

(c) The Author(s) 2021

\begin{abstract}
The paper considers a firm that has the option to invest in a project with an unknown profitability, which is affected by general market uncertainty. The project has the adverse effect that it can cause environmental damage. In case the firm has the option to undertake preventive investment at the time of market entry, we get that preventive investment is significant when (i) the project revenue is large, (ii) the environmental incidents potentially cause a huge reduction of firm value, and (iii) when preventive investment substantially decreases the probability of environmental damage occurrence. The optimality of such a preventive investment results in a significant delay of the project investment. When the firm has the possibility to invest in the project first and do the preventive investment later, this will accelerate the project investment and will result in a larger preventive investment when it indeed will decide to do that one later.
\end{abstract}

Keywords Preventive investment $\cdot$ Real options $\cdot$ Environmental risk

\section{Introduction}

Environmental awareness has prompted many governments to introduce regulations that stimulate cleaner and safer ways of production. Despite these measures, a large number of environmental incidents occurs regularly as a result of industrial development posing

Maria Lavrutich

maria.lavrutich@ntnu.no

1 Center, Department of Econometrics and Operations Research, Tilburg University, Tilburg, The Netherlands

2 Department of Economics, University of Antwerp, Antwerp, Belgium

3 Department of Industrial Economics and Technology Management, Norwegian University of Science and Technology, 7491 Trondheim, Norway

4 Department of Mathematics and CEMAT, Instituto Superior Técnico, Av. Rovisco Pais, 1049-001 Lisboa, Portugal

5 ISEG - School of Economics and Management, Universidade de Lisboa, Rua do Quelhas 6, Lisboa 1200-781, Portugal

6 REM-Research in Economics and Mathematics, CEMAPRE, Lisboa, Portugal 
a threat to environment and local communities. These include, for example, air pollution, chemical and oil spills, water contamination etc. In many cases, however, major pollution incidents can be prevented if appropriate measures are in place. Typically, the companies involved in such incidents are not directly liable for their consequences, which may discourage them from taking appropriate prevention measures. On the other hand, there exists empirical evidence that the occurrence of environmental incidents has a negative impact on the firm's value. For example, Lundgren and Olsson (2010) find a significant negative value loss for European companies that incurred incidents in violation of international environmental norms. Furthermore, these effects may reach beyond the violating company itself. In an example from the automotive industry, Jacobs and Singhal (2020) find a statistically significant negative effect of the September 2015 Volkswagen emissions scandal on the stock prices of its suppliers and customers. The negative stock price reaction creates monetary incentives for the companies to increase expenditures to mitigate environmental risks, which will in turn affect the incentive to invest in polluting projects in the first place. Several early contributions in environmental finance suggest that better environmental management practices, such as investments in abatement capital, reduce the firms' systematic risk and, thus, positively affect the stock prices (Hamilton 1995; Feldman et al. 1997).

In this article, we study the optimal timing of investment decisions in projects with a potential for environmental hazard. In our model, the firm can, to some extent, control the amount of environmental risk they are willing to bear. In particular, the firms may undertake a voluntary preventive investment to reduce the intensity of environmental incidents. We investigate the incentives of polluting firms to introduce preventive measures either at the moment of investment or at a later moment in time, as well as the impact of these measures on the initial decision to undertake such projects.

Among the recent examples of well-publicized environmental disasters is an oil spill from a power plant owned by Nornickel in Russia, in May 2020. ${ }^{1}$ As a result of this incident, 21000 tonnes of oil have contaminated surrounding rivers with the risk to a further spread into the Arctic Ocean, causing an immediate stock price decline of $7.5 \%$. The company was subsequently blamed for operating ageing reservoirs which did not undergo proper refurbishments and, thus, using a dangerous facility in an irresponsible way. Another recent example in mining is the Brumadinho dam disaster in Brazil, in January 2019. The dam owned by iron ore mining company Vale released a mudflow that damaged surrounding buildings, agricultural areas and local ecosystem, as well as numerous deaths. In the aftermath of the disaster, Vale market value experienced a $14 \%$ decline. $^{3}$

There exists a large body of research that investigates the economic consequences of rare events on investment decisions (Martzoukos and Trigeorgis 2002). The uncertain arrival of such events is typically modelled as a Poisson process and includes a wide range of applications. Several studies focus on the impact of positive jumps as a result of technological innovation (Farzin et al. 1998; Huisman 2001; Hagspiel et al. 2020). Another example is policy uncertainty related to either retraction or introduction of favorable regulations, which can result in both positive and negative jumps (Lundgren and Olsson 2010; Chronopoulos et al. 2016; Dalby et al. 2018). Among the early contributions that specifically consider the impact of catastrophic events on investment is Yin and Newman (1996)

\footnotetext{
1 https://www.theguardian.com/environment/2020/jun/09/russian-mining-firm-accused-of-using-globalheating-to-avoid-blame-for-oil-spill

${ }^{2}$ https://meduza.io/en/feature/2020/06/08/the-situation-is-dire

3 https://www.economist.com/business/2019/03/09/vale-and-the-aftermath-of-a-devastating-dam-failure
} 
that investigates the application to forestry. Farrow and Hayakawa (2002) analyzes a real options problem of a safety investment in the presence of catastrophic incidents risk from the regulator's perspective. Dolan et al. (2018) presents a real options valuation model for the mining industry accounting for extreme climate events such as floods and droughts. However, none of the models so far assume that the firms can actively affect the probability of catastrophic events. More specifically, the likelihood of the rare events is considered constant and exogenous to the firm. Our contribution to this stream of literature is that the arrival rate of environmental incidents can be to some extent controlled by the firm as it is able to choose the optimal size of preventive investment.

Our study is also related to the literature on pollution abatement investment (Beavis and Dobbs 1986; Hartl 1992). The focus of this early literature is, however, primarily on the compliance with environmental regulations and the incentives to over-comply are not considered. Several papers attempt to explain the reasons behind voluntary abatement investment by consumer preferences, competition and the specifics of the regulatory framework (Arora and Gangopadhyay 1995; Lundgren 2003; Maxwell and Decker 2006). The closest contribution to our model is Lundgren (2003) that studies voluntary investment in abatement capital under uncertainty. The uncertain factors he considers are future evolution of green goodwill, competition and the threat of regulation, modelled by a Poisson jump process. He finds that incentives to undertake voluntary abatement investment are positively related to regulation intensity and competitors' investment, and negatively related to green goodwill uncertainty. Unlike our paper, most of this literature, however, disregards the direct incentive to reduce the risk of environmental disasters by investing in environmentally friendly technologies. In our model, the reason for over-investment in mitigation of environmental risk comes from the ability of the firm to decrease the arrival rate of incidents by optimally timing and sizing preventive investment.

In this regard, the paper is also related to the growing literature on capacity optimization in a real options framework. Traditionally, a real options model determines the optimal investment timing for a given investment size (Dixit and Pindyck 1994). The main conclusion here is that in more uncertain environments the firms have incentives to delay their investment. More recent contributions allow the firms to choose the optimal size of the investment in addition to timing (Dangl 1999; Huisman and Kort 2015; Huberts et al. 2015). The general conclusion of this stream of literature is that uncertainty increases not only the investment timing, but also the investment size. In these models, the channel through which capacity choice affects the profitability of firms' investment is demand. In our model the channel is the risk of environmental incidents. Thus, we contribute to this literature by providing a link between the optimal size of preventive investment and the possibility to increase the project profitability by reducing the environmental risks.

Our main findings are the following. Undertaking preventive investments is optimal when there is much to protect, i.e. the project revenue is large, when the preventive investment is efficient in reducing the probability of the occurrence of environmental incidents, or when environmental incidents are very damaging with respect to reducing the project value. Preventive investments can be done at the time that the firm invests in the project or later. In the first case it delays investment timing, because the total investment outlay is relatively large. Still it is optimal to do so in cases when there is a lot of uncertainty and the impacit of the incident is considerable.

The paper is organized as follows. Section 2 presents and analyzes our model of preventive investment. Comparative statics results are given in Sect. 3. Section 4 extends the setting of Sect. 2 by allowing the firm to invest in prevention later than just at the same time of market entry. Section 5 concludes. 


\section{Baseline Model of Preventive Investment}

Consider a firm that faces an opportunity to invest in a project with uncertain profitability by undertaking an investment $I_{0}$. Apart from environmental risk, the value of this project is subject to market uncertainty. In particular, the project value is stochastic and evolves according to a geometric Brownian motion

$$
d X_{t}=\mu X_{t} d t+\sigma X_{t} d Z_{t},
$$

where $d Z_{t}$ is the increment of a Wiener process, whereas $\mu$ and $\sigma$ represent the drift and volatility parameters, respectively.

In addition to market risk, the firm is also exposed to environmental accident risk. Such accidents represent technical failures that have a serious negative impact on the environment. The regulator requires the firm to make a mandatory preventive investment of minimal size $R_{0}$ to reduce the environmental risk when undertaking the project. This preventive investment amount is proportional to the investment cost, so that $R_{0}=r_{0} I_{0}$ as large scale projects intuitively require larger preventive investments than small scale projects. Thus, $r_{0}$ represents the rate of mandatory preventive investment. With the minimal preventive measures, the environmental incidents occur according to a Poisson process $N=\left\{N_{t}, t>0\right\}$ with intensity $\lambda_{0}$ (failure rate), where $N_{t}$ denotes the number of incidents that have occurred until time $t$. Every time an environmental incident occurs, the firm value experiences a decline. We let $U_{i}$ denote the (random) percentage reduction in the revenue due to the $i$ th incident, with $\left\{U_{i}, i \in N\right\}$ being a sequence of independent and identically distributed random variables with $\mathbb{E}\left(U_{i}\right)=u$, independent of the Poisson process and of the geometric Brownian motion.

In order to reduce the impact of incidents, the firm has the possibility to undertake a voluntary preventive investment of size $R$ to reduce environmental hazard in addition to the minimal investment amount required by the regulators. Similar to the mandatory preventive investment, the size of the voluntary preventive investment is proportional to the investment cost, so that $R=r I_{0}$, where $r$ represents the rate of voluntary preventive investment. Such an investment decreases the arrival rate of environmental incidents to $\lambda(r)$, with $\lambda^{\prime}(r)<0$ and $\lambda^{\prime \prime}(r)>0$.

In order to maximize the project value, the firm intends to find both the optimal time $\tau^{*}$ and the optimal preventive investment rate $r^{*}$ that would decrease the likelihood of having incidents. Then the firm is facing the following control problem:

$$
V(x)=\sup _{\tau, r} \mathbb{E}_{x}\left[\int_{\tau}^{\infty} X_{t} \prod_{i=1}^{N_{t-\tau}}\left(1-U_{i}\right) \mathrm{e}^{-\rho t} d t-I_{0}\left(1+r_{0}+r\right) \mathrm{e}^{-\rho \tau}\right],
$$

where $I_{0}$ denotes the project investment, $r_{0}$ is the mandatory preventive investment rate, $r$ is the voluntary preventive investment rate that is additional to $r_{0}$, and $\rho$ denotes the discount rate.

In our baseline model, we assume that both investment decisions must be undertaken at the same time. This can occur, for example, in order to comply with environmental standards, due to the regulation measuring environmental safety. Later, we relax this assumption and let the firm decide upon the optimal timing of both investments.

Note that the problem in (2) can be rewritten as follows 


$$
V(x)=\sup _{\tau} \mathbb{E}_{x}\left[\mathrm{e}^{-\rho \tau} \mathbb{E}_{X_{\tau}}\left[\int_{0}^{\infty} X_{t} \mathbb{E}\left[\prod_{i=1}^{N_{t}}\left(1-U_{i}\right)\right] \mathrm{e}^{-\rho t} d t\right]-I_{0}\left(1+r_{0}+r\right) \mathrm{e}^{-\rho \tau}\right],
$$

where

$$
\mathbb{E}\left[\prod_{i=1}^{N_{t}}\left(1-U_{i}\right)\right]=\mathbb{E}\left[(\mathbb{E}(1-U))^{N_{t}}\right]=\sum_{n=0}^{\infty} \frac{\mathrm{e}^{-\lambda(r) t}(\lambda(r) t)^{n}}{n !}(1-u)^{n}=\mathrm{e}^{-\lambda(r) u t}
$$

Further, note that

$$
\mathbb{E}_{x}\left[\int_{0}^{\infty}\left(X_{t} \mathrm{e}^{-\lambda(r) u t}-c\right) \mathrm{e}^{-\rho t} d t\right]=\frac{x}{\rho-\mu+\lambda(r) u},
$$

Therefore, our problem becomes

$$
\sup _{\tau, r} \mathbb{E}_{x}\left[\mathrm{e}^{-\rho \tau}\left(\frac{X_{\tau}}{\rho-\mu+\lambda(r) u}-I_{0}\left(1+r_{0}+r\right)\right)\right] .
$$

Without optimization with respect to $r$, this becomes a standard investment problem, for which the expected total payoff of the investment undertaken for a given level of $x$ and investment rate $r$, is given by:

$$
v(x ; r)=\frac{x}{\rho-\mu+\lambda(r) u}-I_{0}\left(1+r_{0}+r\right),
$$

Given that $\lambda^{\prime}(r)<0$, it is evident that the increase in investment rate, $r$, has an ambiguous effect on the project value $v(x ; r)$. On the one hand, mitigation of environmental hazard becomes more costly, meaning that the firm requires a larger profitability to justify the investment. On the other hand the probability of an environmental incident is decreased, making the investment opportunity more profitable, so that the firm is more eager to invest. We can show that the latter effect is dominating for low values of $r$ and the former for large values, so that there exists a unique optimal preventive investment amount.

Let $r^{*}(x)$ be such that

$$
r^{*}(x)=\underset{r}{\operatorname{argmax}}\left(\frac{x}{\rho-\mu+\lambda(r) u}-I_{0}\left(1+r_{0}+r\right)\right),
$$

so that $r^{*}(x)$ is the value of $r$ that maximizes the expected return of the investment, given that the investment decision is taken when the project profitability is equal to $x$. Then, the solution of problem (6) is given in Proposition 1.

Proposition 1 For the optimization problem (6), the corresponding value function is given by

$$
V_{R}(x)= \begin{cases}A x^{\beta} & \text { if } x \leq x^{*} \\ v\left(x ; r^{*}(x)\right) & \text { if } x>x^{*}\end{cases}
$$

where $\beta$ is equal to 


$$
\beta=\frac{1}{2}-\frac{\alpha}{\sigma^{2}}+\sqrt{\left(-\frac{1}{2}+\frac{\alpha}{\sigma^{2}}\right)^{2}+\frac{2 \rho}{\sigma^{2}}}>1
$$

and the parameters $A$ and $x^{*}$ are implicitly defined by

$$
\left\{\begin{array}{l}
\frac{x^{*}}{\rho-\mu+\lambda\left(r^{*}\left(x^{*}\right)\right) u}\left(1-\frac{1}{\beta}\right)-I_{0}\left(1+r_{0}+r^{*}\left(x^{*}\right)\right)=0, \\
A=\frac{1}{\beta\left(x^{*}\right)^{\beta-1}\left(\rho-\mu+\lambda\left(r^{*}\left(x^{*}\right)\right) u\right)} .
\end{array}\right.
$$

In order to proceed with the calculations, we need to specify a particular functional form for $\lambda(r)$. In the following example we specify the failure rate as

$$
\lambda(r)=\frac{1}{a+b I_{0}\left(r_{0}+r\right)},
$$

with $a, b, r_{0}>0$. A large value of $a$ implies that the project is relatively safe in the sense that occurrence of environmental damage is unlikely even in the absence of preventive investments. A large value of $b$ indicates that preventive investments are efficient in the sense that undertaking them will reduce the probability of the occurrence of environmental incidences considerably.

This particular function belongs to the family commonly called inverse power law relationship, and appears as a straight line when plotted on a log-log scale. Inverse power laws have been proposed to describe at least parts of the frequency-magnitude distributions of landslides, wildfires, windstorms, and other natural processes; see, for example, Turcotte et al. (2002).

Therefore we are assuming a failure rate whose logarithm depends linearly on the mandatory investment rate $r_{0}$ and on the voluntary preventive investment rate, $r$. As $a, b>0$, the larger is $r$ (the maximization variable), the smaller is the failure rate. Moreover, $\lambda(r)$ is bounded by the value $1 /\left(a+b I_{0} r_{0}\right)$, and for each unit of $r$, the failure rate decreases by a factor that depends on $b I_{0}$.

But in fact the results that we present below can be easily generalized for other functional forms, as long as $\lambda^{\prime}(r)<0$ and $\lambda^{\prime \prime}(r)>0$.

In this case the optimal maintenance investment level is given by

$$
r^{*}(x)=\max \left[\frac{1}{I_{0}}\left(\frac{\sqrt{b u x}-u}{b(\rho-\mu)}-\frac{a+b I_{0} r_{0}}{b}\right), 0\right] .
$$

Note that in some scenarios it is not optimal to make a preventive investment at all. As evident from (12), this may happen when the revenue at the time of investment is small ( $x$ is low), the failure rate without preventive investment is already low ( $a$ is large), the incidents do not have a large impact on the revenue ( $u$ is small), or the preventive investment does not have a large impact on the arrival of incidents ( $b$ is small).

The next proposition presents the results for the optimal investment threshold given that the firm spends $r^{*}(x)$ on mitigation of environmental hazard at the moment of investment.

Proposition 2 It is only optimal for the firm to enter the market once the project profitability reaches the optimal investment threshold, $x^{*}$, which is given by 


$$
x^{*}=\left\{\begin{array}{l}
x_{R}^{*} \quad \text { if } \frac{\left(a+b I_{0} r_{0}\right)^{2}\left(\rho-\mu+\frac{u}{a+b I_{0} r_{0}}\right)(\beta-1)}{b u \beta}-I_{0}\left(1+r_{0}\right) \leq 0, \\
x_{0}^{*} \text { if } \frac{\left(a+b I_{0} r_{0}\right)^{2}\left(\rho-\mu+\frac{u}{a+b I_{0} r_{0}}\right)(\beta-1)}{b u \beta}-I_{0}\left(1+r_{0}\right)>0,
\end{array}\right.
$$

where

$$
\begin{gathered}
x_{R}^{*}=\frac{1}{b}\left(\frac{(2 \beta-1) \sqrt{u}+\sqrt{4(\beta-1) \beta(\rho-\mu)\left(b I_{0}-a\right)+u}}{2(\beta-1)}\right)^{2}, \\
x_{0}^{*}=\frac{\beta}{(\beta-1)}\left(\rho-\mu+\frac{u}{a+b I_{0} r_{0}}\right) I_{0}\left(1+r_{0}\right) .
\end{gathered}
$$

Upon investment the firm chooses the following preventive investment rate:

$$
r^{*}\left(x^{*}\right)= \begin{cases}r^{*}\left(x_{R}^{*}\right) & \text { if } \frac{\left(a+b I_{0} r_{0}\right)^{2}\left(\rho-\mu+\frac{u}{a+b b_{0} r_{0}}\right)(\beta-1)}{b u \beta}-I_{0}\left(1+r_{0}\right)<0, \\ 0 & \text { if } \frac{\left(a+b I_{0} r_{0}\right)^{2}\left(\rho-\mu+\frac{u}{a+b I_{0} r_{0}}\right)(\beta-1)}{b u \beta}-I_{0}\left(1+r_{0}\right) \geq 0 .\end{cases}
$$

Moreover,

$$
x_{R}^{*}>\frac{\beta}{(\beta-1)}\left(\rho-\mu+\frac{u}{a+b I_{0} r_{0}}\right) I_{0}\left(1+r_{0}\right),
$$

meaning that a positive preventive investment results in later investment.

As can be seen from Proposition 2, we can distinguish between two situations (depending on parameter values) that affect the initial investment timing: when the firm invests a positive amount in environmental hazard mitigation $\left(r^{*}>0\right)$ and when it never makes a preventive investment $\left(r^{*}=0\right)$. The crucial difference between these situations is that a positive preventive investment requires an additional cost and, hence, results in a delay of the project investment.

\section{Comparative Statics}

Our baseline parameter values are based on the example from the oil industry. The investment cost and the required preventive investment amount are project specific and vary significantly. We choose to set $I_{0}=600$ and $r_{0}=\frac{1}{6}$ and later investigate the sensitivity of the model results with respect to these parameter values. The parameter $b$ is a scale parameter that determines the sensitivity of the incidents arrival rate with respect to preventive investment amount and is set to $b=0.005$ in our baseline case. The frequency of environmental incidents according to the data set of Lundgren and Olsson (2010) is 1 per year for the oil industry. Hence, we set our baseline arrival rate to $\lambda_{0}=1$, which together with $b=0.005, r_{0}=\frac{1}{6}$ and $r=0$ (which means that in the baseline we assume that the company only undertakes the mandatory investment), implies that 


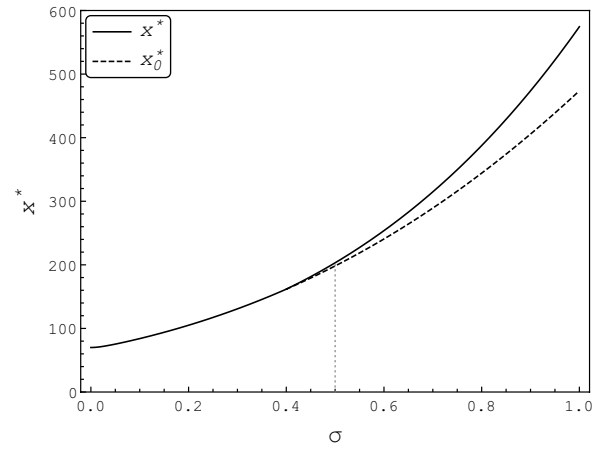

(a) Optimal investment threshold.

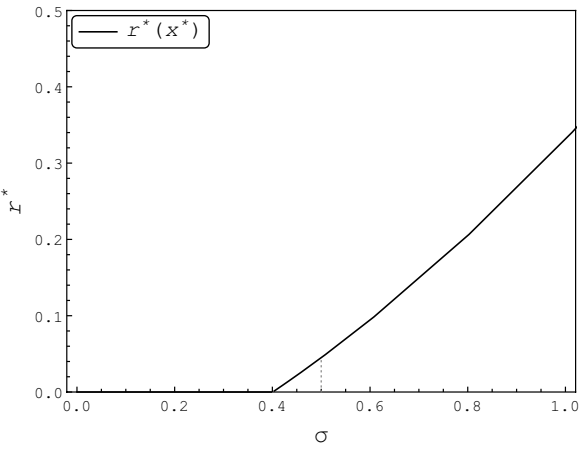

(b) Optimal preventive investment rate.

Fig. 1 Optimal investment threshold and optimal preventive investment rate as functions of $\sigma$. [Parameter values: $\rho=0.09, \mu=0.01 a=0.5, b=0.005, u=0.01, I_{0}=600$ and $r_{0}=\frac{1}{6}$ ]

$\frac{1}{a+b I_{0} r_{0}}=1 \Leftrightarrow a=0.5$. In industries such as oil and gas environmental incidents appear more frequently than, for example, in utilities. We will address these differences by performing a sensitivity analysis with respect to $a$ and $b$. As a baseline, we use a conservative average decline in the project value price due to an environmental incident of $1 \%$, implying that $u=0.01$.

In line with Kellogg (2014), we set the discount rate for the oil project, $\rho$, to $9 \%$. In accordance with Costa Lima and Suslick (2006), we set the volatility of the oil project to $\sigma=0.5$, and the drift to $\mu=0.01$. Here we use their insight that the volatility of oil projects is larger than that of the oil price process. For example, the oil price volatility $20 \%$ translates into the project volatility of $50-60 \%$, where we choose a more conservative estimate.

To summarize, the baseline parameter values that we use are: $\rho=0.09, \sigma=0.5$, $\mu=0.01 a=0.5, b=0.005, u=0.01, I=700$, where $I_{0}=600$ and $r_{0}=\frac{1}{6}$ The figures below illustrate the optimal investment thresholds as well as the optimal preventive investment amount as functions of different parameters. In all figures, the black curve represents the optimal investment threshold for a firm having the option to invest in additional preventive measures, whereas the dashed curve represents the optimal investment threshold in the situation where the firm does not have this option. The vertical dotted lines correspond to the optimal investment threshold and the optimal preventive investment amount for our baseline parameter values.

Figure 1a is according to the standard result in the real options literature that a larger volatility leads to a larger investment threshold, which means that the firm requires a larger level of profitability to undertake the investment. As a result, the firms is also able to allocate a larger investment amount to preventive measures, as illustrated in Fig. 1b.

Figure 2 shows how the investment decision is affected by a change in the average jump size $u$.

As can be seen, increased average damage makes the project less attractive and therefore delays project investment. In addition, increased average damage also raises the need for a larger preventive investment, which in turn also delays project investment.

Figures 3 and 4 depict the effect of the parameters that affect the arrival rate of the environmental incidents. Here, $a$ is inversely related to the arrival rate of incidents also when the firm does not undertake any voluntary investment, whereas $b$ reflects the sensitivity of the inverse arrival rate to the preventive investment amount. 


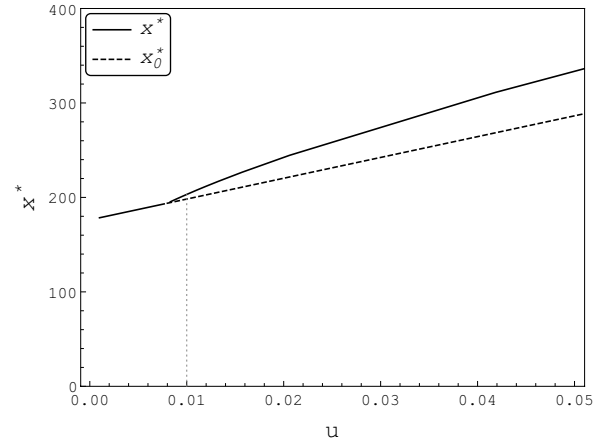

(a) Optimal investment threshold.

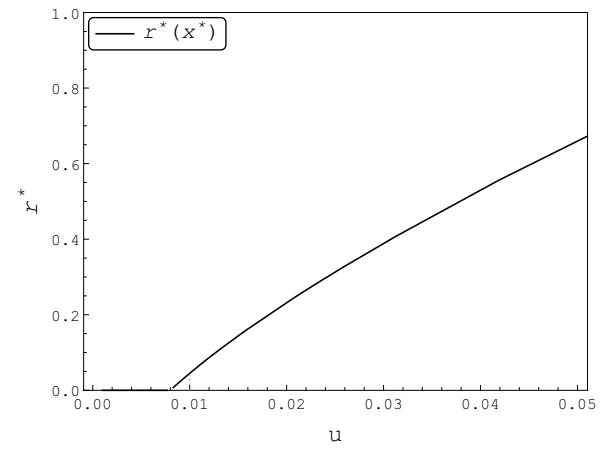

(b) Optimal preventive investment rate.

Fig. 2 Optimal investment threshold and optimal preventive investment rate as functions of $u$. [Parameter values: $\rho=0.09, \sigma=0.5, \mu=0.01 a=0.5, b=0.005, I_{0}=600$ and $r_{0}=\frac{1}{6}$ ]

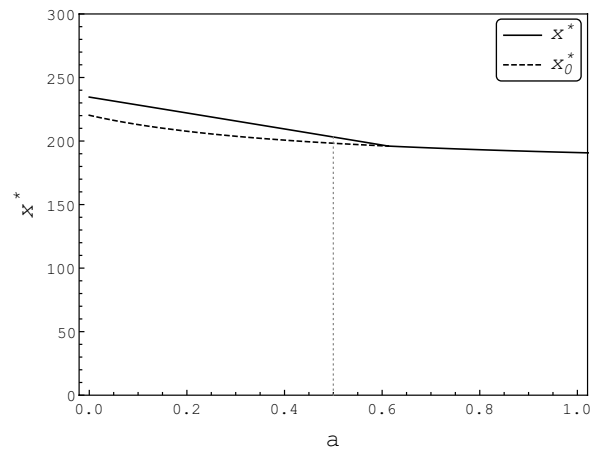

(a) Optimal investment threshold.

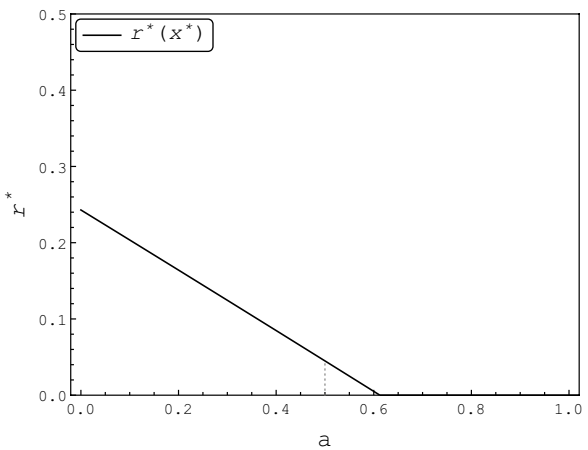

(b) Optimal preventive investment rate.

Fig. 3 Optimal investment threshold and optimal preventive investment rate as functions of $a$. [Parameter values: $\rho=0.09, \sigma=0.5, \mu=0.01, b=0.005, u=0.01, I_{0}=600$ and $\left.r_{0}=\frac{1}{6}\right]$

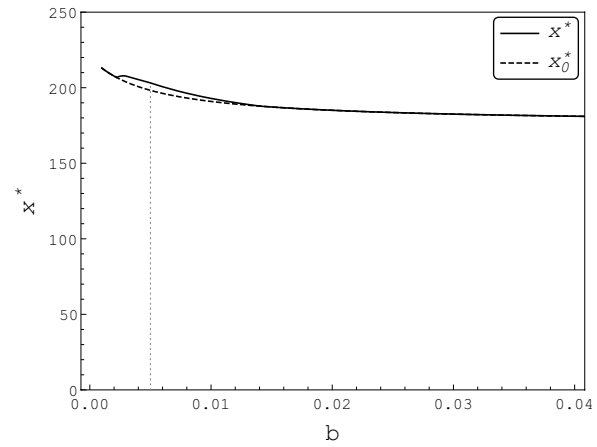

(a) Optimal investment threshold.

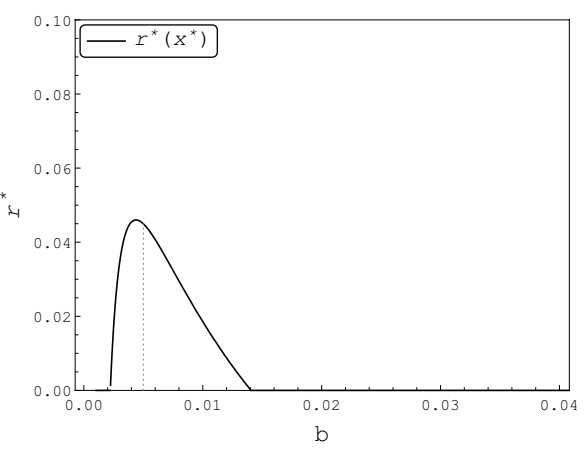

(b) Optimal preventive investment rate.

Fig. 4 Optimal investment threshold and optimal preventive investment rate as functions of $b$. [Parameter values: $\rho=0.09, \sigma=0.5, \mu=0.01 a=0.5, u=0.01, I_{0}=600$ and $r_{0}=\frac{1}{6}$ ] 


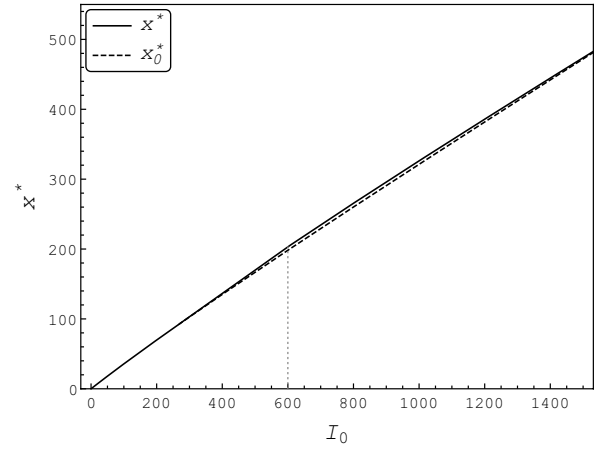

(a) Optimal investment threshold.

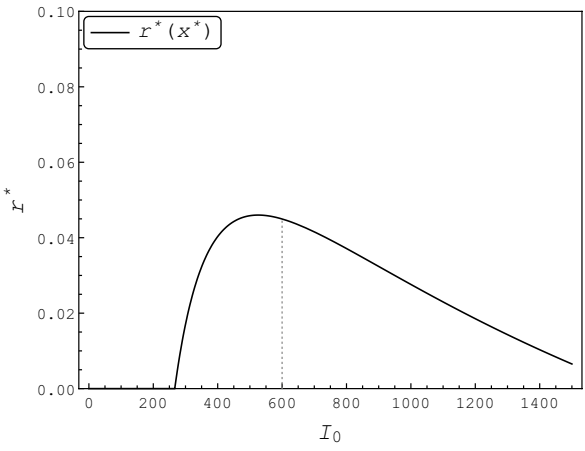

(b) Optimal preventive investment rate.

Fig. 5 Optimal investment threshold and optimal preventive investment rate as functions of $I_{0}$. [Parameter values: $\rho=0.09, \sigma=0.5, \mu=0.01 a=0.5, b=0.005, u=0.01$, and $r_{0}=\frac{1}{6}$ ]

If $a$ is large, implying that the arrival rate of incidents is small even without an additional investment, the preventive investment becomes less necessary. This leads to a smaller investment cost and, thus, earlier investment.

An increase in $b$ results in a non-monotonic effect on both the investment threshold and the optimal size of the preventive investment. When $b$ is small, an increase in preventive investment leads to a smaller effect on the arrival rate of incidents. Then a larger $b$ raises the effectiveness of preventive investment and, therefore, the firm invests more. For large values of $b$, the arrival rate is more sensitive to changes in preventive investment size, resulting in the additional effect that already a small preventive investment substantially reduces the incidents' arrival rate. Therefore, in this $b$-domain, the optimal size of preventive investment is decreasing in $b$. The optimal investment threshold follows the behavior of the optimal $r$. A larger preventive investment makes the project more expensive, which induces a later investment and vice versa.

Figure 5 shows the effect of the project investment amount. A larger investment amount makes the firm investing later, implying that at the moment of investing the profitability of the project is larger. This enlarges the desire to avoid environmental incidences, resulting in additional voluntary preventive investments for $I_{0}$ large enough. As can be seen from Fig. 5, the optimal preventive investment rate changes non-monotonically with investment cost, $I_{0}$. This is because the total preventive investment amount is proportional to $I_{0}$. More specifically, for small $I_{0}$, the benefit of an additional reduction in failure rate outweighs an increase in total investment cost and, thus, $r^{*}$ increases. For a large $I_{0}$, a large enough the reduction in failure rate can be achieved by a smaller $r^{*}$ and, thus, the firm invests preventively at a smaller rate.

Figure 6 illustrates the effect of a change in the required preventive investment amount on firm's investment timing and size decisions.

In fact, total preventive investment being equal to $\left(r_{0}+r^{*}\right) I_{0}$ is constant. If the required preventive investment amount is large, less additional preventive investment is needed to reduce the arrival rate of incidents. Therefore, a larger $r_{0}$ negatively affects $r^{*}$. If total preventive investment goes up, project value increases and the firm invests later. This explains why $x^{*}$ increases in $r_{0}$. 


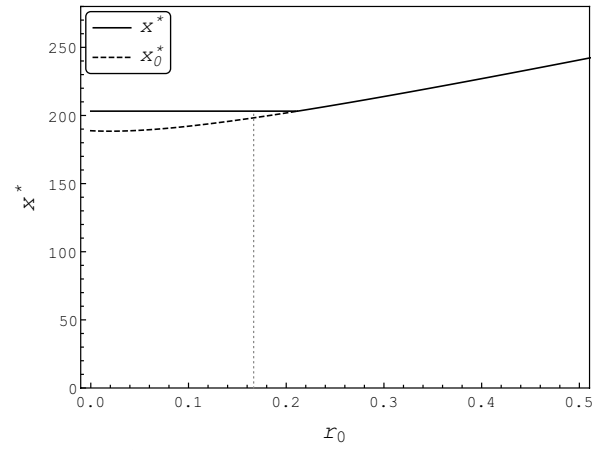

(a) Optimal investment threshold.

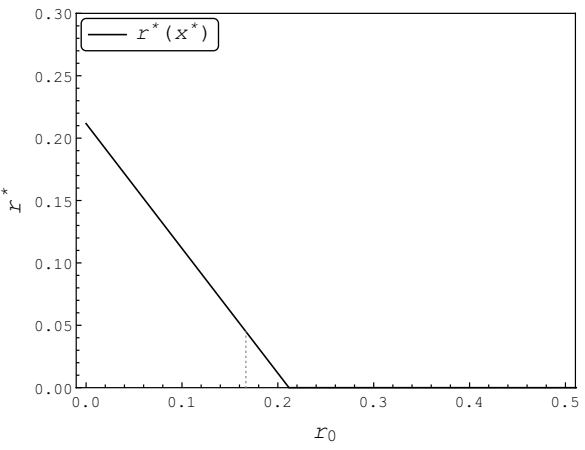

(b) Optimal preventive investment rate.

Fig. 6 Optimal investment threshold and optimal preventive investment rate as functions of $r_{0}$. [Parameter values: $\rho=0.09, \sigma=0.5, \mu=0.01 a=0.5, b=0.005, u=0.01$, and $I_{0}=600$.]

\section{Discretion Over Timing of Preventive Investment}

In the previous section the firm is obliged to undertake preventive investment at the time it initiates the project. Thus, both investment decisions occur simultaneously.

In this section, the firm have the opportunity to undertake the voluntary preventive investment after the project investment already has been undertaken. Consequently, we have to determine:

1. When to invest in the project;

2. Upon investment, when to make the voluntary preventive investment.

After the firm has invested in the project, it is subject to accidents. Since these reduce the project's profitability, the number of accidents occurred so far is a relevant input to the voluntary preventive investment decision. Consequently, in order to formulate an optimal preventive policy, the firm needs to keep record of the number of accidents occurred so far.

Next to the timing of the preventive investment, we still also have to determine the investment size. The relevant value function to determine the timing and the size of the voluntary preventive investment is the one that arises after the firm has undertaken the project investment. This value function can be expressed as follows:

$$
\begin{aligned}
V_{1}(x, n) & =\sup _{\tau, r \geq 0} \mathbb{E}_{x, n}\left[\int_{0}^{\tau} \mathrm{e}^{-\rho t} X_{t} \prod_{i=1}^{N_{t}}\left(1-U_{i}\right) d t-I_{0} r \mathrm{e}^{-\rho \tau}\right. \\
& \left.+\int_{\tau}^{\infty}\left(X_{t} \prod_{i=1}^{N_{\tau}}\left(1-U_{i}\right) \prod_{i=1}^{N_{t-\tau}^{R}}\left(1-U_{i}\right)\right) \mathrm{e}^{-\rho t} d t\right],
\end{aligned}
$$

where $N^{R}$ is the Poisson process with intensity rate $\lambda(r)$. To find the optimal timing of the project investment, we have to maximize the project value, which includes the option to invest in voluntary preventive investment. From the moment the project is started environmental incidences can occur. However, before that time incidences are absent. For that 
reason the value function of the optimization problem to be solved just depends on $x$ and not on $n$. The corresponding optimization problem can be expressed as

$$
\begin{aligned}
V_{2}(x) & =\sup _{\tau_{1} \leq \tau_{2}, r \geq 0} \mathbb{E}_{x}\left[\int_{\tau_{1}}^{\tau_{2}} \mathrm{e}^{-\rho t}\left(X_{t} \prod_{i=1}^{N_{t-\tau_{1}}}\left(1-U_{i}\right)\right) d t-I_{0}\left(1+r_{0}\right) \mathrm{e}^{-\rho \tau_{1}}\right. \\
& \left.+\int_{\tau_{2}}^{\infty}\left(X_{t} \prod_{i=1}^{N_{\tau_{2}-\tau_{1}}}\left(1-U_{i}\right) \prod_{i=1}^{N_{t-\tau_{2}}^{R}}\left(1-U_{i}\right)\right) \mathrm{e}^{-\rho t} d t-I_{0} r e^{-\rho \tau_{2}}\right],
\end{aligned}
$$

in which $\tau_{1}$ denotes the time of the project investment, and $\tau_{2}$ is the time of the preventive investment. Of course it has to hold that $\tau_{1} \leq \tau_{2}$, as the preventive investment only makes sense after the project has started.

Similar arguments as the ones used in the previous section lead us to conclude that solving (18) is the same as solving:

$$
V_{1}(x, n)=\frac{x}{\rho+u \lambda(0)-\mu}+\sup _{\tau, r \geq 0} \mathbb{E}_{x, n}\left[e^{-\rho \tau} h\left(X_{\tau}, N_{\tau} ; r\right)\right],
$$

where

$$
h(x, n ; r)=(1-u)^{n} x\left(\frac{1}{\rho+u \lambda(r)-\mu}-\frac{1}{\rho+u \lambda(0)-\mu}\right)-I_{0} r .
$$

Using the strong Markov property, it follows that the problem described by $V_{2}$ is related with $V_{1}$ as follows:

$$
V_{2}(x)=\sup _{\tau} E_{x}\left[e^{-\rho \tau}\left(V_{1}\left(X_{\tau}, 0\right)-I_{0}\left(1+r_{0}\right)\right)\right] .
$$

The standard real options analysis learns that the solution of the optimization problem (22) is as follows:

$$
V_{2}(x)= \begin{cases}C x^{\beta} & x<x_{I} \\ V_{1}(x, 0)-I_{0}\left(1+r_{0}\right) & x \geq x_{I}\end{cases}
$$

where $x_{I}$ denotes the optimal project investment threshold. As usual, $C$ and $x_{I}$ can be derived using the smooth fit conditions:

$$
C x_{I}^{\beta}=V_{1}\left(x_{I}, 0\right)-I_{0}\left(1+r_{0}\right), \quad \beta C x_{I}^{\beta-1}=\left.\frac{d V_{1}(x, 0)}{d x}\right|_{x=x_{I}} .
$$

Therefore in order to solve the problem for $V_{2}$, we need first to solve for $V_{1}$. And this means that we need to maximize with respect to the investment rate $r$ and the preventive investment time $\tau_{2}$.

We start by regarding the maximization with respect to $r$. It follows from (21), that the effect of $r$ on the terminal value has an ambiguous effect, as in the baseline model. The firm will invest an amount $r^{*}(x, n)$ given by

$$
r^{*}(x, n)=\underset{r \geq 0}{\operatorname{argmax}} h(x, n ; r) .
$$


For the particular case $\lambda(r)=\frac{1}{a+b I_{0}\left(r_{0}+r\right)}$, the firm will invest the following quantity in the preventive center:

$$
r^{*}(x, n)=\max \left[\frac{1}{I_{0}}\left(\frac{-u+\sqrt{b(1-u)^{n} u x}}{b(\rho-\mu)}-\frac{a+b I_{0} r_{0}}{b}\right), 0\right] .
$$

If the condition $\frac{-u+\sqrt{b(1-u)^{n} u x}}{b(\rho-\mu)}-\frac{a+b I_{0} r_{0}}{b}>0$ does not hold, the preventive investment will not take place.

This leads straightforwardly to the following result.

Proposition 3 The preventive investment amount $r^{*}(x, n)$ decreases with the number of incidents and increases in the revenue.

Regarding the optimal time to undertake the voluntary preventive investment, we note that the value of the corresponding investment option, $V_{1}$, can be obtained by solving the following equation:

$$
r v(x, n)-\mathcal{L} v(x, n)=0
$$

with $\mathcal{L}$ given by

$$
\mathcal{L} v(x, n)=\mu x v^{\prime}(x, n)+\frac{\sigma^{2}}{2} x^{2} v^{\prime \prime}(x, n)+\lambda_{0}(v(x, n+1)-v(x, n)),
$$

where the last term represents the expected revenue loss in case one accident occurs. An analytical solution to differential equation (25) is not possible to find, as discussed in Nunes et al. (2021). Consequently, one can only find the numerical threshold values for the initial investment, which we denote by $\bar{x}_{I}^{*}$, as well as preventive for the investment denoted by $\bar{x}_{n}^{*}$. Therefore, in the Appendix we present a quasi-analytical solution for the problem described in (18).

\subsection{Comparative Statics}

In this section, we present the comparative statics result for the model where preventive investment and initial investment do not necessarily have to occur at the same time. In the subsequent figures the blue solid threshold curve represents the initial investment threshold and the black solid curve corresponds to the preventive investment decision (timing and size). The black dashed curve is the investment decision when both investments occur at the same time (baseline model). Again, the vertical dotted lines correspond to the optimal investment threshold and the optimal preventive investment amount for our baseline parameter values (Fig. 7).

Figure 1 shows that as uncertainty increases, both investments occur later. However, the gap between preventive investment and initial investment becomes smaller. For sufficiently large $\sigma$ the firm directly invest preventively when initiating the project, despite the fact that sequential investment is allowed. This is because for higher uncertainty the initial investment occurs when the project profitability is larger. This implies that environmental incidences will cause a larger reduction of the firm value, which increases the need for preventive investment. Also, the initial investment occurs earlier in the extended model in comparison to the baseline model in case the firm indeed decides to 


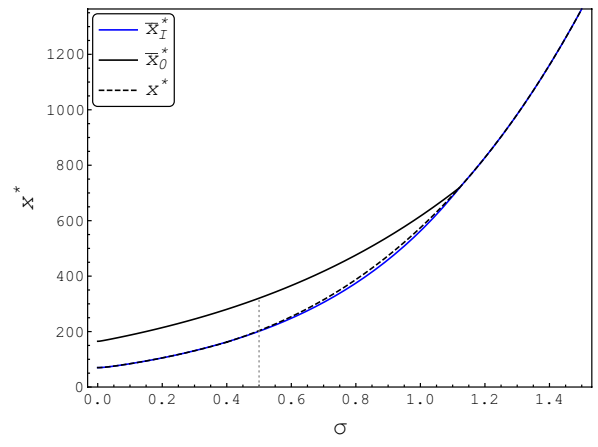

(a) Optimal investment thresholds.

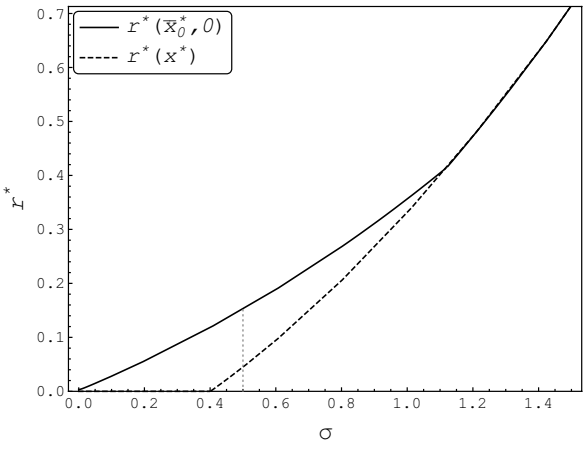

(b) Optimal preventive investment rate.

Fig. 7 Optimal investment thresholds and optimal preventive investment rate as functions of $\sigma$. [Parameter values: $\rho=0.09, \mu=0.01, a=0.5, b=0.005, u=0.01, I_{0}=600$, and $r_{0}=\frac{1}{6}$ ]

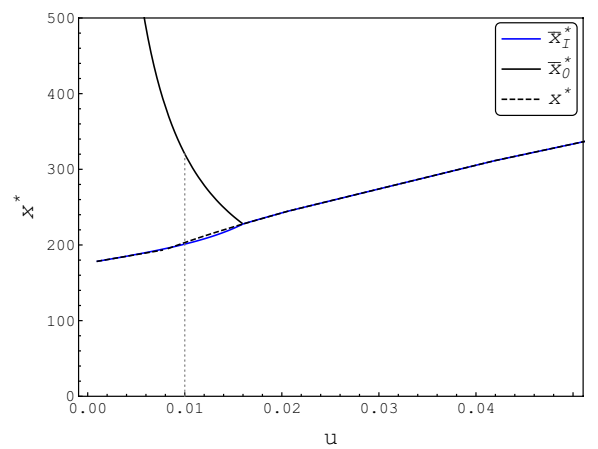

(a) Optimal investment thresholds.

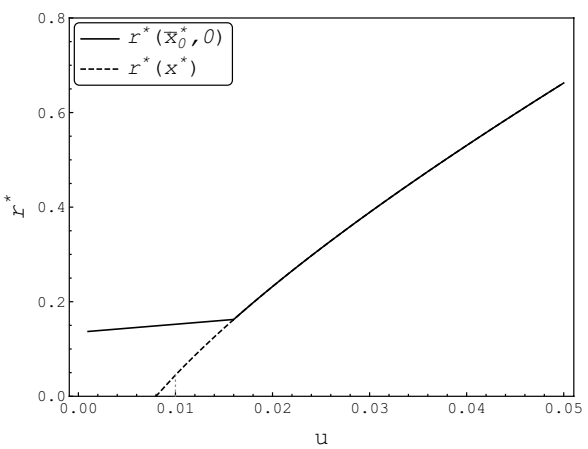

(b) Optimal preventive investment rate.

Fig. 8 Optimal investment thresholds and optimal preventive investment rate as functions of $u$. [Parameter values: $\rho=0.09, \sigma=0.5, \mu=0.01, a=0.5, b=0.005, I_{0}=600$, and $\left.r_{0}=\frac{1}{6}\right]$

undertake the preventive investment later. This is because the possibility to undertake the preventive investment later increases the initial investment profitability. Therefore, the firm is more eager to invest and does it earlier. Another reason for earlier initial investment occurs when in the baseline model the firm decides to undertake voluntary preventive investment. This increases the investment outlay in the baseline model and therefore the firm invests later in that case. It is also important to note that preventive investments increase in size when they are undertaken at a later point in time than the project investment. The obvious explanation is that project profitability is larger at the moment the firm makes the preventive investment.

As the impact of the incidents, $u$, increases, preventive investment timing decreases, whereas its size increases, as depicted in Fig. 8. The more damaging the incidents are, the more eager is the firm to invest more in preventing them. Consequently, the gap between initial investment and preventive investment decreases in $u$. When $u$ is sufficiently large, initial and preventive investment occur at the same time, despite the fact that a sequential investment occurrence is allowed. 


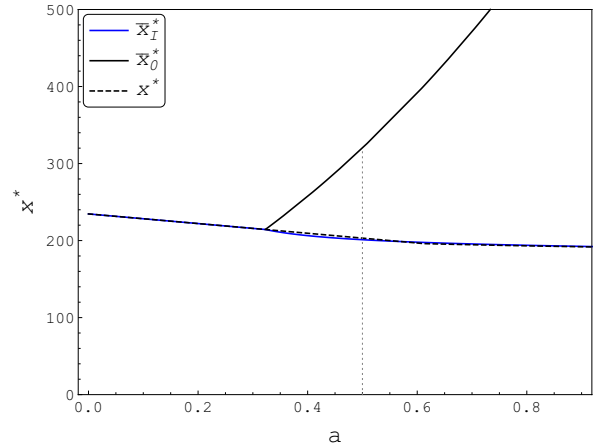

(a) Optimal investment thresholds.

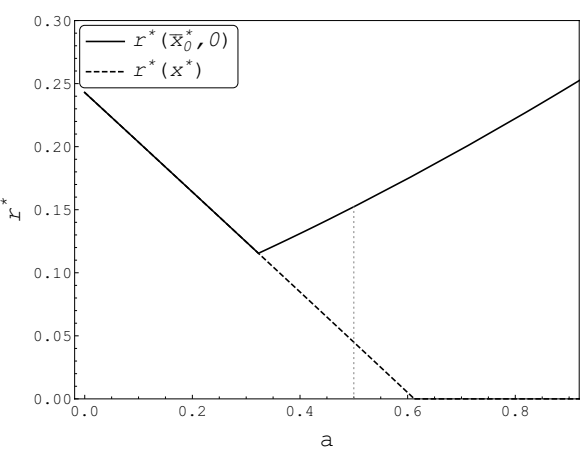

(b) Optimal preventive investment rate.

Fig. 9 Optimal investment thresholds and optimal preventive investment rate as functions of $a$. [Parameter values: $\rho=0.09, \sigma=0.5, \mu=0.01, b=0.005, u=0.01, I_{0}=600$, and $r_{0}=\frac{1}{6}$ ]

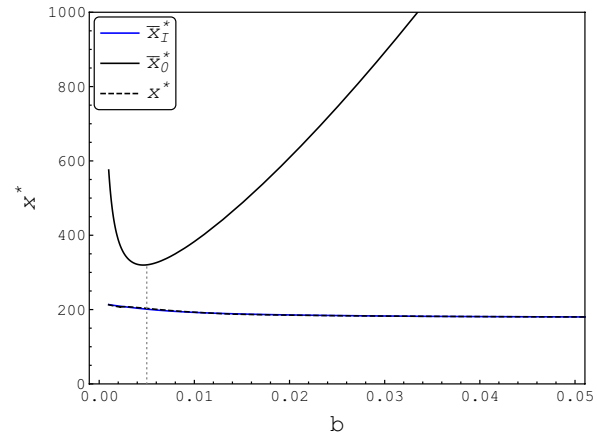

(a) Optimal investment thresholds.

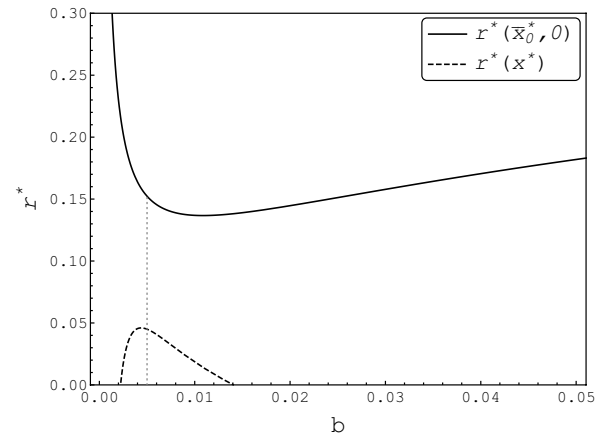

(b) Optimal preventive investment rate.

Fig. 10 Optimal investment thresholds and optimal preventive investment rate as functions of $b$. [Parameter values: $\rho=0.09, \sigma=0.5, \mu=0.01, a=0.5, u=0.01, I_{0}=600$, and $\left.r_{0}=\frac{1}{6}\right]$

As seen in Fig. 9, the larger is $a$, the lower is the likelihood of incidents' arrivals. Then a preventive investment becomes less necessary, so it happens later. The latter means that the project profitability is higher at the moment of the preventive investment, and therefore the firm will increase the preventive investment size. As a result, the gap in timing between preventive investment and initial investment increases in $a$. A small enough value of a implies that "action" is needed to limit occurrence probability of environmental incidences. Therefore, the firm does not become active without investing preventively. Consequently, in such a situation the firm invests simultaneously in the project and in preventive means, despite the fact that investing sequentially is allowed.

The preventive investment threshold is non-monotonic in $b$, as shown in Fig. 10. On the one hand, the larger is $b$ the more efficient the preventive investment is, which incentivizes the firm to invest sooner. On the other hand, the larger is $b$ the more efficient is the mandatory investment, $R_{0}=r_{0} I_{0}$. In this case, the firm does not need to undertake additional voluntary preventive investments as the required investment reduces the incident arrivals by a lot already. Therefore, it invests later, and thus more since there are more revenues to protect at that time. In this example the mandatory investment $I_{0} r_{0}=100$ is so large that it 


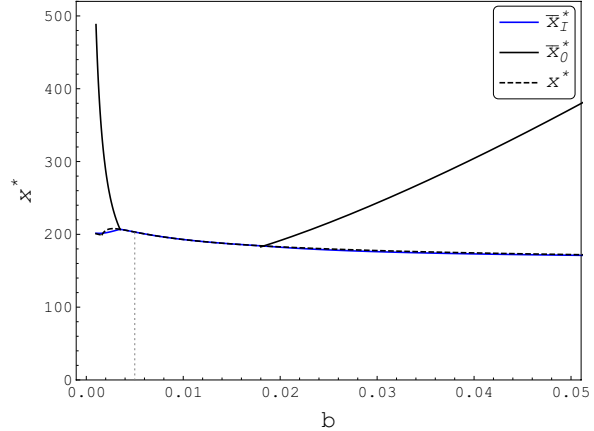

(a) Optimal investment thresholds.

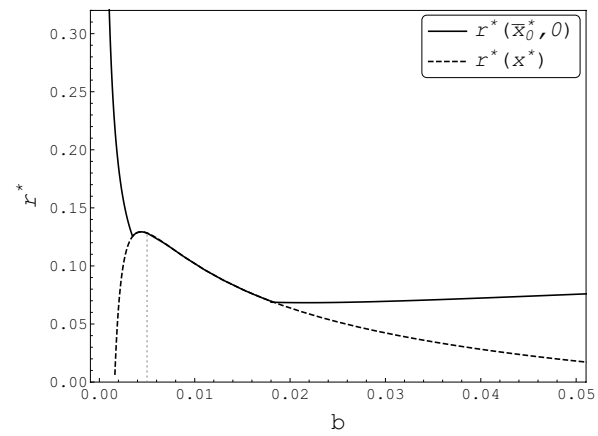

(b) Optimal preventive investment rate.

Fig. 11 Optimal investment thresholds and optimal preventive investment rate as functions of $b$. [Parameter values: $\rho=0.09, \sigma=0.5, \mu=0.01, a=0.5, u=0.01, I_{0}=600$, and $r_{0}=\frac{1}{12}$.]

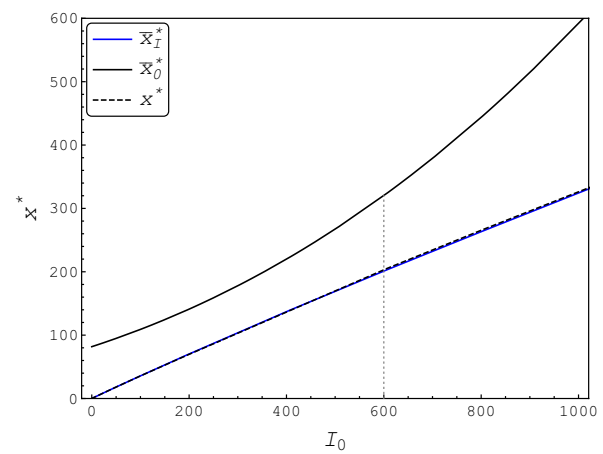

(a) Optimal investment thresholds.

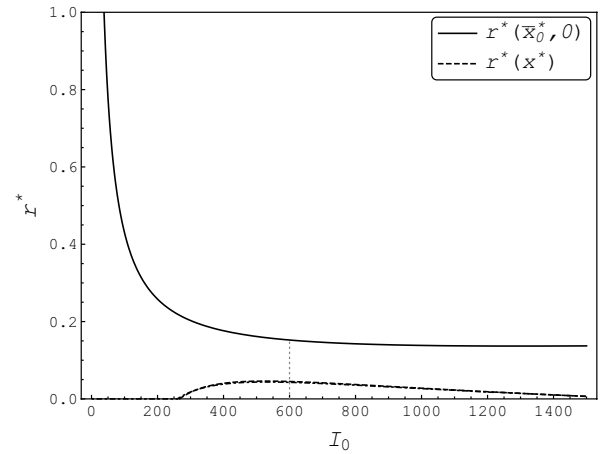

(b) Optimal preventive investment rate.

Fig. 12 Optimal investment thresholds and optimal preventive investment rate as functions of $I_{0}$. [Parameter values: $\rho=0.09, \sigma=0.5, \mu=0.01, a=0.5, b=0.005, u=0.01$, and $r_{0}=\frac{1}{6}$ ]

always makes sense to wait with preventive investment and not to do it immediately after the initial investment. This is obviously not the case if we decrease the rate of mandatory preventive investment $r_{0}$, as confirmed in Fig. 11 where $r_{0}=\frac{1}{12}$, and, consequently, $I_{0} r_{0}=50$. Here it holds that for intermediate levels of $b$ both investments happen at the same time. This indicates that policies regarding mandatory measures to prevent incidents have a substantial impact on the investment strategies of firms (Fig. 12).

Figure 11 depicts the effect of different levels of $I_{0}$. The larger is $I_{0}$ the later the initial investment happens, which is according to intuition. Furthermore, unlike in the baseline model, a larger $I_{0}$ reduces the preventive investment rate. The reason behind this is that in case the investment times are separated, an investment cost $I_{0}$ does not affect the preventive investment directly but rather though a total preventive investment amount $r^{*} I_{0}$. Thus, given $I_{0}$ the firm is able to choose the total preventive investment size by setting $r^{*}$. Intuitively, the larger the $I_{0}$ is, the smaller $r^{*}$ is necessary to sufficiently reduce the arrival rate of environmental incidences. In addition, as we see in Fig. 11, for our chosen parameter set, when the firm has the option to invest sequentially, it never chooses $\bar{x}_{I}^{*}=x^{*}$, and, thus, investing sequentially is always preferable to simultaneous investment. 


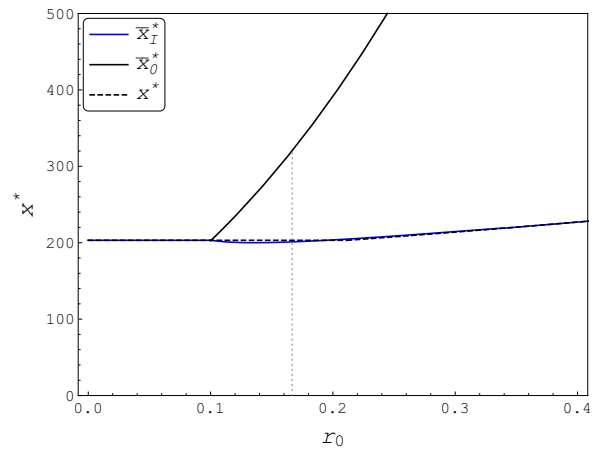

(a) Optimal investment thresholds.

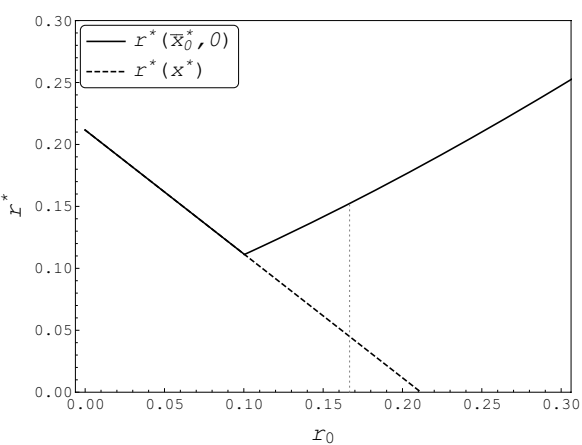

(b) Optimal preventive investment rate.

Fig. 13 Optimal investment thresholds and optimal preventive investment rate as functions of $r_{0}$. [Parameter values: $\rho=0.09, \sigma=0.5, \mu=0.01, a=0.5, b=0.005, u=0.01$, and $I_{0}=600$.]

Figure 13 shows that the larger is $r_{0}$ the less incentives has the firm to invest additionally in prevention of environmental incidents. Thus, preventive investment happens later (and, thus, is of larger size). However, a small mandatory investment implies huge environmental risks if the firm starts the project without undertaking any additional preventive investments. Therefore, for $r_{0}$ small enough the firm goes for the simultaneous investment even when a sequential investment policy is also allowed.

\section{Conclusion}

Ample industrial projects exist that go along with risks of having environmental incidents. Although firms need not always be liable, the common denominator is that such incidents will reduce firm value. It is therefore important to analyze the option to invest in a project together with the option to undertake preventive investments that reduce the probability of occurrence of such environmental incidents.

In this paper, we first consider project investment in the case that preventive investment should occur at the same time. We find that preventive investments are large when (i) the project revenue is large, (ii) the environmental incidents potentially cause a huge reduction of firm value, and (iii) when preventive investment substantially decreases the probability of environmental damage occurrence. In these situations the firm is inclined to invest more when it wants to start such an industrial project, and this will lead to a considerable delay.

Next, we take a more sequential view on the investment strategies in the sense that we give the firm the option to undertake the preventive investment at a later point in time than the project investment. We identify two new effects if we compare the investment outcome to our first model. First, the firm decides to start the industrial project sooner, because the initial sunk costs are smaller. Second, the firm undertakes a larger preventive investment. This is because preventive investment occurs later, meaning that then the project's revenue is larger. Hence, there is more to lose for this firm, which thus incentivizes the desire to increase the preventive investment.

In what follows, we discuss an interesting topic for future research. In our model the mandatory preventive investment $r_{0}$ is exogenous. It would be interesting to investigate what is the optimal level of mandatory preventive investment from the point of view of 
the regulator. The most obvious objective of the regulator is to maximize welfare. Welfare consists of taking the sum of producer and consumer surplus, as usual, but in addition it is negatively affected by environmental damage. Of course environmental damage is already included in the producer surplus, but besides reduction in the firm value it has a bigger negative effect on society. In such a setting $r_{0}$ has different effects. First, it takes care of minimum environmental prevention efforts by the firm, which reduces the danger of environmental damage. Second, it makes investment more expensive, can therefore delay undertaking the project, which has a negative effect on consumer surplus. Third, it reduces the feasible region of the firm, which could in some cases imply a reduction of producer surplus. So, establishing the optimal level of mandatory preventive investment is not trivial and therefore an interesting problem to investigate.

\section{Appendix}

\section{A Numerical Approximation}

We propose a quasi-analytical solution for the problems described in (18) and, consequently, (22), based on a truncation method. By truncated problem we mean that in the definition of $V_{1}$ we impose an additional constraint on the admissible stopping times. In this case, we assume there is a number of accidents sufficiently large for which the corresponding value function is zero, regardless of the value $x$ of the project. We let $\bar{N}$ denote such value and we let $\bar{V}_{1}^{*}(x, n)$ denote the value function when the project value is $x$, and $n$ accidents have already occurred, for the truncated problem. Furthermore, we let $\tau_{\bar{N}}$ be the time at which the $\bar{N}$ accident occurs.

The truncated problem corresponding to (18) is defined as follows:

$$
\begin{aligned}
\bar{V}_{1}^{*}(x, n) & =\sup _{\tau \leq \tau_{\bar{N}}, r \geq 0} \mathbb{E}_{x, n}\left[\int_{0}^{\tau} \mathrm{e}^{-\rho t} X_{t} \prod_{i=1}^{N_{t}}\left(1-U_{i}\right) d t-r \mathrm{e}^{-\rho \tau}\right. \\
& \left.+\int_{\tau}^{\infty}\left(X_{t} \prod_{i=1}^{N_{\tau}}\left(1-U_{i}\right) \prod_{i=1}^{N_{t-\tau}^{* *}}\left(1-U_{i}\right)\right) \mathrm{e}^{-\rho t} d t\right],
\end{aligned}
$$

which means that in (26) the optimal stopping time is bounded above by $\tau_{\bar{N}}$, whereas in (18) it does not have such restriction. The meaning of such truncation comes from the following. Let $\tilde{h}(x, n)=h\left(x, n ; r^{*}(x, n)\right)$, so that $\tilde{h}(x, n)$ represents the terminal cost if the firm decides to invest in the preventive center when the profit is $x, n$ accidents have already occurred and the firm invests an optimal value $r^{*}(x, n)$. Note that for each $x$, there is a number of accidents $n(x)$ for which $\tilde{h}(x, n)<0, \forall n \geq n(x)$. Therefore, intuitively one expects to have $\bar{N}=\sup \{n(x): \tilde{h}(x, n)<0, \forall x, \forall n \geq n(x)\}$.

We use the notation - to denote that we are using the truncation method, and $*$ to denote that we have optimized with respect to the preventive investment. We assume that $\bar{V}_{1}^{*}(x, \bar{N})=0, \forall x$. Moreover, we let $\bar{x}_{n}^{*}$ denote the level of the project that triggers the preventive investment, given that $n$ accidents have already occurred and $n \leq \bar{N}$.

As the $h$ function, as defined on (21), is decreasing in $n$, for a fixed $x$, it follows that $\bar{x}_{n}^{*}$ increases in $n$, i.e., for $n_{1}<n_{2}$, the firm requires a larger profit to make the preventive investment when the number of accidents occurred so far is $n_{2}$ than when it is $n_{1}$. Therefore, one may expect waiting/investment regions as depicted in Fig. 14. 


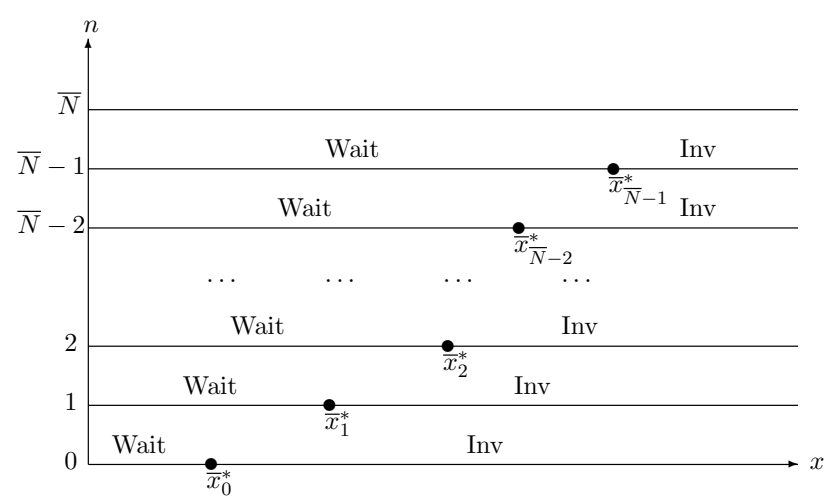

Fig. 14 Optimal strategy for preventive investment

Following Nunes et al. (2021), after some manipulations in order to consider our set-up, we end up with the following expressions for the solution of problem (26).

$$
\bar{V}_{1}^{*}(x, \bar{N}-i)=\frac{x}{\rho+u \lambda(0)-\mu}+ \begin{cases}\sum_{j=0}^{i-1} A_{N-i, j}(\ln x)^{j} x^{d_{2}} & x<\bar{x}_{\bar{N}-i}^{*}, \\ h\left(x, \bar{N}-i ; r^{*}(x, \bar{N}-i)\right) & x \geq \bar{x}_{\bar{N}-i}^{*},\end{cases}
$$

with

$$
A_{m, j}=-\frac{2 \lambda_{0}}{\sigma^{2}} \sum_{l=j-1}^{\bar{N}-2-m}(-1)^{l-j+1} \frac{l !}{j !} \frac{A_{m+1, l}}{\left(d_{2}-d_{1}\right)^{l+2-j}}
$$

for $j \geq 1$,and

$$
A_{n, 0}=\left(\bar{x}_{n}^{*}\right)^{-d_{2}} \tilde{h}(x, n)-\left(A_{n, 1} \ln \left(\bar{x}_{n}^{*}\right)+\left(\sum_{j=2}^{\bar{N}-n-1} j A_{n, j}\left(\ln \left(\bar{x}_{n}^{*}\right)\right)^{j}\right) \chi_{\{n \neq \bar{N}-2\}}\right) \chi_{\{n \neq \bar{N}-1\}},
$$

and the thresholds satisfy the equations

$$
\begin{aligned}
& \left(\bar{x}_{n}^{*}\right)^{d_{2}}\left(A_{n, 1}+\left(\sum_{j=2}^{\bar{N}-n-1} j A_{n, j}\left(\ln \left(x_{n}^{*}\right)\right)^{j-1}\right) \chi_{\{n \neq \bar{N}-2\}}\right) \chi_{\{n \neq \bar{N}-1\}} \\
& +(1-u)^{\bar{N}-1}\left(d_{2}-1\right) \bar{x}_{n}^{*}\left(\frac{1}{\rho+\lambda\left(r^{*}\left(\bar{x}_{n}^{*}, n\right)\right) u-\mu}-\frac{1}{\rho+\lambda(0) u-\mu}\right)-d_{2} r^{*}\left(\bar{x}_{n}^{*}, n\right)=0 .
\end{aligned}
$$

In the above equations, $d_{1}$ and $d_{2}$ are the roots of the characteristic polynomial $\frac{\sigma^{2}}{2} d(d-1)+\mu d-(\rho+\lambda)$ : 


$$
\begin{aligned}
& d_{1}=\frac{\left(\frac{\sigma^{2}}{2}-\mu\right)+\sqrt{\left(\frac{\sigma^{2}}{2}-\mu\right)^{2}+2 \sigma^{2}(\rho+\lambda)}}{\sigma^{2}}>1 \text { and } \\
& d_{2}=\frac{\left(\frac{\sigma^{2}}{2}-\mu\right)-\sqrt{\left(\frac{\sigma^{2}}{2}-\mu\right)^{2}+2 \sigma^{2}(\rho+\lambda)}}{\sigma^{2}}<0 .
\end{aligned}
$$

The analytical computation of the coefficients $A_{m, j}$ is not possible, but computationally does not lead to any problem. Consequently, one can only find the thresholds $\bar{x}_{\bar{N}-i}^{*}$ (for $i=2, \ldots, \bar{N})$ and $\bar{x}_{I}^{*}$ using numerical values.

\section{B Proofs}

Proof of Proposition 1 The value matching and smooth pasting conditions lead to the following system of equations:

$$
\left\{\begin{array}{l}
A x^{* \beta}=v\left(x^{*}, r^{*}\left(x^{*}\right)\right), \\
\beta A x^{*} \beta-1=\frac{\partial}{\partial x^{*}} v\left(x^{*}, r^{*}\left(x^{*}\right)\right)+\frac{\partial}{\partial r^{*}\left(x^{*}\right)} v\left(x^{*}, r^{*}\left(x^{*}\right)\right) \frac{\partial r^{*}\left(x^{*}\right)}{\partial x^{*}},
\end{array}\right.
$$

where in the last equation we use the total derivative rule in order to compute $\frac{\partial v\left(x^{*}, r^{*}(x)\right)}{\partial x^{*}}$.

Taking into account the definition of $r^{*}$, it follows that $\frac{\partial}{\partial r^{*}\left(x^{*}\right)} v\left(x^{*}, r^{*}\left(x^{*}\right)\right)=0$, and therefore the system (11) becomes

$$
\left\{\begin{array}{l}
A\left(x^{*}\right)^{\beta}=\frac{x^{*}}{\rho-\mu+\lambda\left(r^{*}\left(x^{*}\right)\right) u}-I_{0}\left(1+r_{0}+r^{*}\left(x^{*}\right)\right), \\
\beta A\left(x^{*}\right)^{\beta-1}=\frac{1}{\rho-\mu+\lambda\left(r^{*}\left(x^{*}\right)\right) u} .
\end{array}\right.
$$

Simplifying yields the expression for $A$

$$
A=\frac{1}{\beta\left(x^{*}\right)^{\beta-1}\left(\rho-\mu+\lambda\left(r^{*}\left(x^{*}\right)\right) u\right)},
$$

and the following implicit equation for the optimal threshold

$$
\frac{x^{*}}{\rho-\mu+\lambda\left(r^{*}\left(x^{*}\right)\right) u}\left(1-\frac{1}{\beta}\right)-I_{0}\left(1+r_{0}+r^{*}\left(x^{*}\right)\right)=0 .
$$

Note that (33) can be represented as the difference between the value of investing and the value of waiting $\frac{x^{*}}{\rho-\mu+\lambda\left(r^{*}\left(x^{*}\right)\right) u}-I_{0}\left(1+r_{0}+r^{*}\left(x^{*}\right)\right)-A\left(x^{*}\right)^{\beta}$, which at the optimal investment threshold should be equal to 0 . Thus, for $x<x^{*}$ it should hold that waiting is more valuable and, thus, $\frac{x^{*}}{\rho-\mu+\lambda\left(r^{*}\left(x^{*}\right)\right) u}-I_{0}\left(1+r_{0}+r^{*}\left(x^{*}\right)\right)-A\left(x^{*}\right)^{\beta}<0$. Thus, this allows us to identify the following condition for the optimal threshold 


$$
\frac{\left(x^{*}-h\right)}{\rho-\mu+\lambda\left(r^{*}\left(x^{*}-h\right)\right) u}\left(1-\frac{1}{\beta}\right)-I_{0}\left(1+r_{0}+r^{*}\left(x^{*}-h\right)\right)<0 \text { for } h \in\left(0, x^{*}\right) .
$$

Proof of Proposition 2 From (12), it follows that $r^{*}(x)$ can be written as

$$
r^{*}(x)= \begin{cases}0, & \text { if } x<\hat{x}, \\ \frac{1}{I_{0}}\left(\frac{\sqrt{b u x}-u}{b(\rho-\mu)}-\frac{a+b I_{0} r_{0}}{b}\right) & \text { if } x \geq \hat{x},\end{cases}
$$

where

$$
\hat{x}=\frac{\left(\left(a+b I_{0} r_{0}\right)(\rho-\mu)+u\right)^{2}}{b u} .
$$

Plugging in the expressions for $r^{*}(x)$ and $\lambda(r)$ in (33), we get that $x^{*}$ is the solution of $F(x)=0$, where

$$
F(x)= \begin{cases}\left(\frac{\beta-1}{\beta}\right) \frac{x}{\rho-\mu+\frac{u}{a+b I_{0} r_{0}}}-I_{0}\left(1+r_{0}\right) & \text { if } x<\hat{x}, \\ \left(\frac{\beta-1}{\beta}\right) \frac{x(-u+\sqrt{b u x})}{\sqrt{b u x}(\rho-\mu)}+\frac{u-\sqrt{b u x}}{b(\rho-\mu)}-I_{0}+\frac{a}{b} & \text { if } x \geq \hat{x} .\end{cases}
$$

As $I_{0}>0$, we can conclude that (37) has at least one solution, because $\left.F(x)\right|_{x \geq \hat{x}}$ is U-shaped parabola. Therefore

$$
x^{*}=\min \{x>0: F(x)=0\},
$$

so that $x^{*}$ is always the smallest positive root of $F(x)=0$.

Since $F(\hat{x})=\frac{\left(a+b I_{0} r_{0}\right)^{2}\left(\rho-\mu+\frac{u}{a+b I_{0} r_{0}}\right)(\beta-1)}{b u \beta}-I_{0}\left(1+r_{0}\right)$, it is optimal to invest $r^{*}>0$, when $\frac{\left(a+b I_{0} r_{0}\right)^{2}\left(\rho-\mu+\frac{u}{a+b b_{0} r_{0}}\right)(\beta-1)}{b u \beta}-I_{0}\left(1+r_{0}\right) \leq 0$, and zero otherwise. Given this condition, solving for $x$ yields the result presented in (13-16). We note that we are able to prove that $r^{*}(x)$ is one and only zero of the first order derivative of $v$ w.r.t. $r$, and that this is exactly the maximizer defined in Eq. (8).

Finally, (17) holds in view of the definition of $F$, (37), and the fact that $F$ has at least one zero.

Funding Open access funding provided by NTNU Norwegian University of Science and Technology (incl St. Olavs Hospital - Trondheim University Hospital).

Open Access This article is licensed under a Creative Commons Attribution 4.0 International License, which permits use, sharing, adaptation, distribution and reproduction in any medium or format, as long as you give appropriate credit to the original author(s) and the source, provide a link to the Creative Commons licence, and indicate if changes were made. The images or other third party material in this article are included in the article's Creative Commons licence, unless indicated otherwise in a credit line to the material. If material is not included in the article's Creative Commons licence and your intended use is not permitted by statutory regulation or exceeds the permitted use, you will need to obtain permission directly from the copyright holder. To view a copy of this licence, visit http://creativecommons.org/licenses/by/4.0/. 


\section{References}

Arora S, Gangopadhyay S (1995) Toward a theoretical model of voluntary overcompliance. J Econ Behav Organ 28:289-309

Beavis B, Dobbs IM (1986) The dynamics of optimal environmental regulation. J Econ Dyn Control 10:415-423

Chronopoulos M, Hagspiel V, Fleten S-E (2016) Stepwise green investment under policy uncertainty. Energy J 37:61944-9089

Costa Lima GA, Suslick SB (2006) Estimation of volatility of selected oil production projects. J Pet Sci Eng 54:129-139

Dalby P, Gillerhaugen G, Hagspiel V, Leth-Olsen T, Thijssen J (2018) Green investment under policy uncertainty and bayesian learning. Energy 161:1262-1281

Dangl T (1999) Investment and capacity choice under uncertain demand. Eur J Oper Res 117:415-428

Dixit A, Pindyck R (1994) Investment under uncertainty. Princeton University Press, Princeton

Dolan C, Blanchet J, Iyengar G, Lall U (2018) A model robust real options valuation methodology incorporating climate risk. Resour Policy 57:81-87

Farrow S, Hayakawa H (2002) Investing in safety: an analytical precautionary principle. J Saf Res 33:165-174

Farzin YH, Huisman KJM, Kort PM (1998) Optimal timing of technology adoption. J Econ Dyn Control 22:779-799

Feldman SJ, Soyka PA, Ameer PG (1997) Does improving a firm's environmental management system and environmental performance result in a higher stock price? J Invest 6:87-97

Hagspiel V, Huisman KJ, Kort PM, Lavrutich MN, Nunes C, Pimentel R (2020) Technology adoption in a declining market. Eur J Oper Res 285:380-392

Hamilton JT (1995) Pollution as news: media and stock market reactions to the toxics release inventory data. J Environ Econ Manag 28:98-113

Hartl RF (1992) Optimal acquisition of pollution control equipment under uncertainty. Manag Sci 38:609-622

Huberts NFD, Huisman KJM, Kort PM, Lavrutich MN (2015) Capacity choice in (strategic) real options models: a survey. Dyn Games Appl 5:424-439

Huisman KJ, Kort PM (2015) Strategic capacity investment under uncertainty. RAND J Econ 46:376-408

Huisman KJM (2001) Technology investment: a game theoretic real options approach. Kluwer Academic Publishers, Dordrecht, The Netherlands

Jacobs BW, Singhal VR (2020) Shareholder value effects of the Volkswagen emissions scandal on the automotive ecosystem. Prod Oper Manag 29(10):2230-2251

Kellogg R (2014) The effect of uncertainty on investment: evidence from Texas oil drilling. Am Econ Rev 104:1698-1734

Lundgren T (2003) A real options approach to abatement investments and green goodwill. Environ Resour Econ 25:17-31

Lundgren T, Olsson R (2010) Environmental incidents and firm value-international evidence using a multifactor event study framework. Appl Financ Econ 20:1293-1307

Martzoukos SH, Trigeorgis L (2002) Real (investment) options with multiple sources of rare events. Eur J Oper Res 136:696-706

Maxwell J, Decker C (2006) Voluntary environmental investment and responsive regulation. Environ Resour Econ 33:425-439

Nunes C, Oliveira C, Pimentel R (2021) Quasi-analytical solution of an investment problem with decreasing investment cost due to technological innovations. J Econ Dyn Control 130:104154

Turcotte DL, Malamud BD, Guzzetti F, Reichenbach P (2002) Self-organization, the cascade model, and natural hazards. Proc Natl Acad Sci 99:2530-2537

Yin R, Newman DH (1996) The effect of catastrophic risk on forest investment decisions. J Environ Econ Manag 31:186-197

Publisher's Note Springer Nature remains neutral with regard to jurisdictional claims in published maps and institutional affiliations. 